\title{
Los cuerpos de la Guerra. Análisis de los procesos de construcción corporal y subjetiva en los militantes
}

The Bodies of War. Analysis of the Processes of Corporal and Subjective Construction in Activists.

\author{
Por: Andrea Lissett Pérez ${ }^{1}$
}

Recibido: junio de 2016 Revisado: noviembre de 2016 Aceptado: diciembre de 2016

\section{Resumen.}

En los procesos de construcción corporal y subjetiva en el contexto del conflicto interno colombiano y, específicamente, entre los militantes del grupo guerrillero del Ejército de Liberación Nacional (ELN), se destaca el sentido de lo colectivo en la construcción de la corporalidad en este grupo guerrillero, estructurada en función del "cuerpo social" como ideal de su proyecto de lucha, derivado de la configuración de una subjetividad fundada en el "nosotros".

Palabras clave. Configuración de subjetividad, Guerra, Ejército de Liberación Nacional, insurgencias colombianas, Corporalidad, Cuerpo social.

\begin{abstract}
.
In the corporal and subjective construction in the context of the Colombian conflict, and specifically, among the militants of the guerrilla group of the National Liberation Army (ELN), the sense of the collective in the construction of the corporality in this guerrilla group stands out. Such a construction is structured on the basis of the "social body" as an ideal of their project of fight, which is derived from the configuration of subjectivity and founded in "us."
\end{abstract}

Key words. Configuration of Subjectivity, War, National Liberation Army (ELN), Colombian Insurgences, Corporality, and Social Body.

\footnotetext{
${ }^{1}$ Antropóloga de la Universidad Nacional de Colombia. Magíster en Antropología Social, Universidad Federal de Santa Catarina, Brasil y doctora en Antropología Social de la misma universidad. Docente de la Universidad de Antioquia. Correo electrónico: andrealizett@gmail.com
} 


\section{Introducción.}

El cuerpo se convirtió en nuestros tiempos en objeto privilegiado de estudio social. Pero, cabe recordar, que no siempre tuvo la misma relevancia; en realidad, hasta entrados los años $80^{\prime}$ del siglo pasado se mantuvo obscurecido bajo el manto de un enfoque biologicista que lo concebía como un hecho dado, natural. De ahí que sea paradigmática la temprana postura de Marcel Mauss, quien, en una conferencia dada en la Sociedad de Psicología en el año de 1934, afirmó que "el objeto y medio técnico más natural del hombre es el cuerpo", argumentando a través de innumerables ejemplos sobre las técnicas corporales existentes en distintos contextos culturales, la relación existente entre el cuerpo y los "símbolos morales e intelectuales" (Mauss, 1991, Pp. 337-342).

La perspectiva de Mauss se convirtió en un referente para las ciencias sociales y particularmente para la Antropología que concibe un nexo inextricable entre el cuerpo y la dimensión sociocultural, en cuyo contexto lo corporal no es solamente comprendido como un objeto de representaciones simbólicas sino también como productor de estas (Maluf, 2002). La corporalidad pasó a ser entendida, entonces, como una construcción social y, como tal, relativa a los distintos contextos sociales e históricos en que sea abordada.

Un caso ejemplar que ayuda a ilustrar esa noción polivalente de cuerpo-cultura, es el relacionado con las sociedades amerindias brasileras de las tierras bajas de América del Sur. Allí, en 1979, los antropólogos Eduardo Viveros, Roberto Da Matta y Anthony Seeger, observaron que el cuerpo ocupaba un lugar central en la sociedad, que trascendía la mirada de "simple soporte de identidad y roles sociales", para convertirse en "matriz de significados sociales y objeto de significación social” (Da Matta; Seeger; Viveiros, 1979, p. 10).

En las sociedades occidentales contemporáneas, el cuerpo también ocupa una posición central, solamente que desde una perspectiva completamente diferente. Ya no como "matriz de significación social", sino en función de la noción hegemónica de individuo, entendido como el recinto objetivo de la soberanía del sujeto y como factor de individualización (Le Breton, 1995). La modernidad, conforme Le Breton, trajo consigo la mirada del cuerpo como objeto, como representación, como valor, como signo y como lugar privilegiado en la construcción de la subjetividad.

En el análisis que hace Sonia Maluf (2002) sobre los enfoques antropológicos que abordan el campo temático del cuerpo, la autora hace una observación sugestiva para la presente reflexión: señala el papel del poder en la construcción corporal, dado que existen: "puntos de vista hegemónicos sobre el cuerpo en las sociedades occidentales urbanas modernocontemporáneas", de modo que "tal vez en el interior de esas culturas y sociedades también sea posible encontrar la diferencia" (Maluf, 2002, p. 88). O sea, se pone en debate la unicidad de las prácticas corporales en las sociedades occidentales contemporáneas.

Este es justamente el propósito del presente artículo: reflexionar en torno al proceso de construcción corporal de los miembros del Ejército de Liberación Nacional (ELN), que es una organización guerrillera clandestina que ha permanecida activa en el territorio colombiano por más de cincuenta años. 
El ELN representa la típica guerrilla del modelo de Revolución Cubana, habiendo surgido, inclusive, en el seno del fervor de la Isla, en 1963, cuando un grupo de jóvenes colombianos, que había partido para la Habana con el fin de estudiar, decidió formar una guerrilla revolucionaria. El primer grupo de agitación y promoción de este proyecto de lucha armada se denominó “Brigada Pro Liberación Antonio Galán”, constituido por estudiantes que retornaron al territorio colombiano para dar vida a esa iniciativa. Los miembros fundadores decidieron instalarse al nororiente colombiano (San Vicente de Chucuri), zona de reconocida trayectoria de lucha y resistencia popular (Pérez, 2008). Allí dan inicio a lo que se denominará la "primera marcha guerrillera", el 4 de julio de 1964, y su primera aparición pública el 7 de enero de 1965, cuando realizan la toma armada del pueblo de Simacota.

Con base en información documental y etnográfica obtenida en el marco de una investigación que buscaba comprender los motivos de la larga duración de esta guerrilla en el contexto colombiano, realizada durante el periodo 2006-2008 (Pérez, 2008), se reconocieron varios tópicos relevantes, tales como los signos de identificación corporal que recrean pautas de relacionamiento y estatus entre los miembros del grupo y las técnicas de adiestramiento corporal que transforman los cuerpos de los militantes en aptos para la guerra. Estos aspectos serán abordados como ámbitos de comprensión de la configuración de un sentido diferenciado de corporalidad en el contexto socio-organizativo de esta guerrilla.

Se defiende la tesis de que, al interior de la sociedad colombiana, y específicamente en contextos de guerra, (Pérez, 2008), prevalecen prácticas corporales disidentes del modelo hegemónico que concibe el cuerpo como valor de individualización, como la existente en el grupo guerrillero del ELN, cuya corporalidad se centra en el sentido de lo colectivo, en que el cuerpo se construye en función de lo social como instrumento de los ideales del grupo. Así, el "cuerpo social" aparece como el ideal a lograr dentro del proceso de reconstrucción corporal y subjetiva. El cuerpo pasa a concebirse como medio de construcción social y proyección de la utopía de lucha.

Los cuerpos adquieren, así, una importancia estratégica en la medida de que se ponen a disposición de los intereses colectivos. Debiendo, para ello, alcanzar ciertas condiciones necesarias que les permita ser útiles a "la causa social". Los cuerpos tienen que ser, por tanto, entrenados, preparados, adecuados para los nuevos requerimientos, tendiendo como ideario los siguientes atributos: ser fuerte, resistente, abstemio, austero, estoico y sacrificado. Es una modalidad de corporalidad que se trabaja físicamente para adquirir las condiciones necesarias para el combate y en lo psicológico-emocional, para tener la capacidad de resistir a la lucha y en ella persistir.

Esta fabricación corporal ejerce un papel decisivo en la construcción del militante eleno y de su nueva subjetividad. Pero, como debe entenderse, este proceso no parte de cero, los sujetos llegan con un aprendizaje sociocultural adquirido dentro del paradigma de individualidad, propio de los discursos y las prácticas hegemónicas de la sociedad occidental contemporánea. De modo que es necesario desarrollar un proceso de reeducación en razón al cambio radical de modelo de vida que, según Berger e Luckmann (1976), debe llevarse a cabo por medio de técnicas pedagógicas intensificadas para intentar abarcar la "totalidad subjetiva" de los iniciados y afectar, así, sus hábitos. 
Este proceso de reeducación es realizado a través del aprendizaje de las técnicas corporales, entendidas, conforme Mauss (1991), como la transmisión cultural de un conjunto de procedimientos, pautas y mecanismos para acondicionar el cuerpo al modelo de interacción corporal. Pero, visto este proceso desde una perspectiva más compleja que incluya las relaciones sociales inmersas, la noción que, probablemente, sea apropiada para pensar esta problemática es la relacionada con el "disciplinamiento" de cuerpos y sujetos (Foucault, 1987). Este concepto es concebido como las "fórmulas generales de dominación”, consolidadas durante los siglos XVII y XVIII, que "permiten el control minucioso de las operaciones del cuerpo que realizan, y que dan como resultado la resignación permanente de sus fuerzas que le imponen una relación de docilidad-utilidad; que son las que podemos llamar de 'disciplinas"' (Foucault, 1987, p. 118).

Obsérvese que aquí está en juego un elemento clave: el poder en relación al cuerpo: “en cualquier sociedad el cuerpo está preso en el interior de poderes muy cerrados, que le imponen limitaciones, prohibiciones u obligaciones" (Foucault, 1987, p. 118). Esta condición corporal no es nueva en la historia ni tampoco característica de una determinada sociedad, pues, siendo el cuerpo escenario fundamental en las relaciones sociales y en la formación de la subjetividad, no podría estar fuera de los circuitos de poder.

Este tipo de dominación corporal por medio de la formación disciplinaria, queda inmerso en las redes sociales, en los micropoderes que someten al sujeto. El poder es tan absoluto que los cuerpos y los sujetos se vuelven simples receptáculos (Foucault, 1983). Nótese que desde este enfoque conceptual no parece haber espacio para formas de resistencia o de diferenciación del modelo hegemónico. Por eso, pese a que se acoja la perspectiva de las disciplinas corporales como formas de moldear y controlar los cuerpos y los sujetos bajo determinadas pautas de comportamiento, también se cuestiona la omnipotencia de las mismas.

Es decir, se concibe la posibilidad de que las técnicas disciplinarias sean confrontadas, subvertidas o resistidas dentro de contextos sociales y políticos donde se expresan distintos intereses. En otras palabras, en la interpretación de este fenómeno se da cabida a la acción subjetiva como respuesta activa de los individuos o de colectivos que buscan a través de los procesos corporales afianzar determinada identidad o proyectar ciertos idearios. Esto no significa que se desconozcan las formas de control social ni que se crea que todos los sujetos tengan plena consciencia de tales procesos.

Las anteriores apreciaciones ayudan a enmarcar el análisis de este artículo, en el que, como ya dicho, se profundiza en algunos aspectos considerados relevantes para entender el sentido de la construcción de la corporalidad en los militantes del ELN. Pero, cabe advertir que esta mirada no agota el complejo universo de estudio de la corporalidad de estos sujetos y sus múltiples perspectivas, solamente ofrece una ruta para avanzar en la comprensión de cómo se edifican cuerpos, sujetos y subjetividades aptos en y para contextos de guerra.

Así mismo, es oportuno señalar que este tópico (corporalidad) no ha sido abordado en la literatura existente sobre el ELN, ni tampoco ha sido reconocido como objeto de especial atención dentro del contexto del conflicto armado colombiano (Blair, 2010).

Los estudios realizados sobre el ELN pueden agruparse en tres categorías: las entrevistas periodísticas realizadas a varios mandos de la organización (Harnecker, 1988; López, 1989), las biografías sobre algunos guerrilleros célebres del grupo (Broderick, 1977, 2000) y las 
investigaciones académicas con énfasis en el componente político y en el historiográfico (Aguilera, 2003, 2007; Bejarano, 2005; Medina, 1996, 2001; Vargas, 1992, 1998).

Sin embargo, se encuentran algunas excepciones notables como, por ejemplo, los trabajos de la antropóloga María Victoria Uribe (1978; 2004), quien ha profundizado en la línea analítica de las masacres como prácticas corporales de guerra normalizadas en la historia nacional, vistas como poderosas armas simbólicas para aterrorizar y controlar. Y más recientemente, ha emergido una reflexión más sistemática sobre corporalidad y sufrimiento en la guerra, en la que sobresalen algunos autores como Elsa Blair, quien, en la misma línea de Uribe, ha abordado el tema de las masacres desde un enfoque antropológico (2004), además de retomar la perspectiva foucultniana que relaciona cuerpo, violencia y poder como "dispositivos o tecnologías corporales para controlar y dominar los cuerpos en distintos ámbitos de la vida social, pero, en el ámbito de la guerra, los cuerpos no ajustados a dichos órdenes son 'castigados': mutilados, violados, desaparecidos, asesinados, torturados...” (Blair, 2010, p. 43).

Otra línea analítica sobre corporalidad y violencia que también se ha posicionado en este campo de estudio en el país, es la psicoanalítica con énfasis en el pensamiento lacaniano (Ver Castro, 2002; Díaz, 2003; Aranguren, 2006; Londoño, 2005).

El presente texto se sitúa en ese horizonte de investigación, pero con ciertas singularidades en la mirada conceptual y en función de un campo etnográfico específico del cual se derivan sus reflexiones: las prácticas corporales en los guerrilleros del ELN.

\section{Metodología.}

Esta investigación debate sobre los procesos de construcción corporal y subjetiva en el contexto del conflicto interno colombiano y, específicamente, entre los militantes del grupo guerrillero del Ejército de Liberación Nacional (ELN).

Fueron usadas fuentes documentales y etnográficas para comprender ese proceso de edificación corporal.

Se exploraron las siguientes dimensiones:

- los signos de identificación corporal como una sintaxis de posiciones y estatus al interior de la organización guerrillera;

- las técnicas de disciplinamiento corporal; y

- la configuración de una subjetividad fundada en el "nosotros".

\section{Resultados.}

\section{Signos de identificación corporal.}

La corporalidad es asumida por muchos sectores sociales contemporáneos como medio privilegiado de identificación, como forma de exteriorización subjetiva, de ganar presencia en el mundo, como ocurre, por ejemplo, con el grupo de "tatuados", que se diferencian por el hecho de estar "cerrando su cuerpo con tatuajes", como un proceso en permanente elaboración y de 
re-significación, en el cual el sujeto, a través de la construcción de su propia corporalidad, se construye a sí mismo (Pérez, 2006).

En el caso de los cuerpos de los guerreros, aunque también pasan por un proceso de revaloración corporal que los marca, los identifica entre sí y los diferencia de los demás, la singularidad consiste en que la identificación no es individual, sino que se orienta por la búsqueda de identidad grupal.

Si concebidos que la corporalidad es un locus privilegiado de la construcción subjetiva, es comprensible que en los cuerpos se inscriban los cambios en la forma de percibir y de posicionarse en el mundo. Esto es lo que ocurre con los elenos, cuya corporalidad cambió notoriamente con el paso del tiempo. Así, puede detectarse que durante la primera época de esta organización (años 1960-1970), cuando carecían de recursos económicos y no poseían uniformes ni armas de dotación, la imagen conocida de estos guerrilleros era la de unos sujetos barbudos, de cabello largo, con boina y con pesadas mochilas a la espalda, abriendo caminos en "el monte" con la firme convicción de "salvar el mundo".

Esa imagen corporal comienza a cambiar ostensivamente a partir de los años ochenta, cuando incorporan en su ajuar elementos altamente distintivos como el uso de uniformes color marrón, portando un brazalete con los colores negro y rojo de su bandera, que los identifica públicamente. Pero, tendrán aún un cambio más radical a comienzos de los años noventa, momento en el que la valoración realizada de ese contexto histórico, los lleva a considerar que se encuentran en un período pre-revolucionario de la toma del poder. En consecuencia, deciden fortalecer sus estructuras armadas, creando un contingente militar conformado por unidades de “ejército" y de "guerrillas locales" que substituirían el modelo inicial de guerrilla móvil.

Estos cambios en su perspectiva política e ideológica, los llevó a adoptar una nueva corporalidad, en la que se destaca la tendencia a enfatizar el componente militar, concebido desde los cánones tradicionales. Esta nueva estética también obedeció a una estrategia generalizada entre los grupos guerrilleros colombianos de incorporar la vestimenta militar camuflada y el corte raso del cabello como una forma de mimetizase con el ejército colombiano dentro de las zonas del conflicto.

Obsérvese las siguientes imágenes que ilustran los tres tipos de corporalidad que han sido producidos a lo largo de la historia del ELN: 


\section{Tipos de corporalidad que han sido producidos a lo largo de la historia del ELN.}

Figura n. 1 Guerrilleros del ELN, años1960

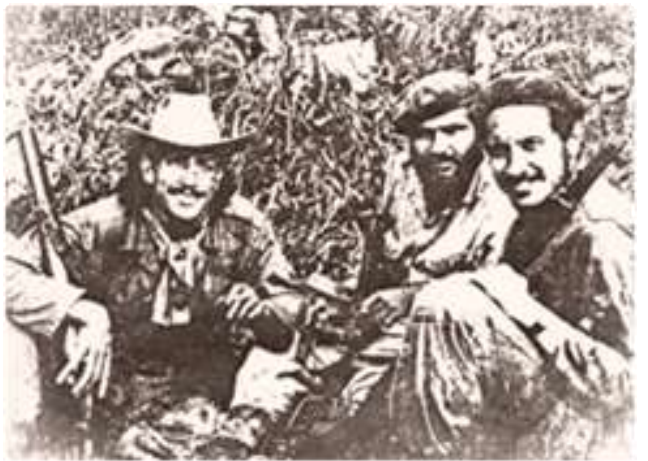

(Voces ELN, sf)
Figura n. 2 Guerrilleros del ELN, 1980.

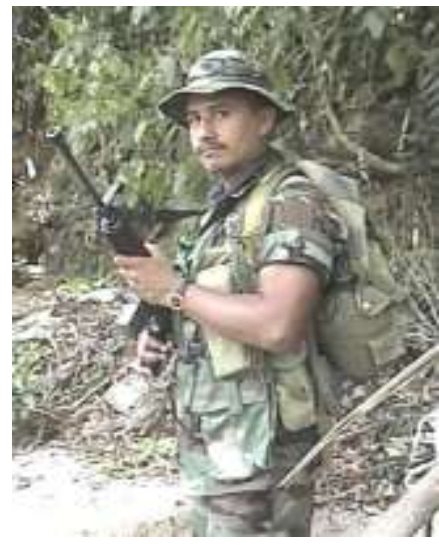

(Voces ELN, sf)
Figura n.3 Guerrilleros del ELN, años 2000.

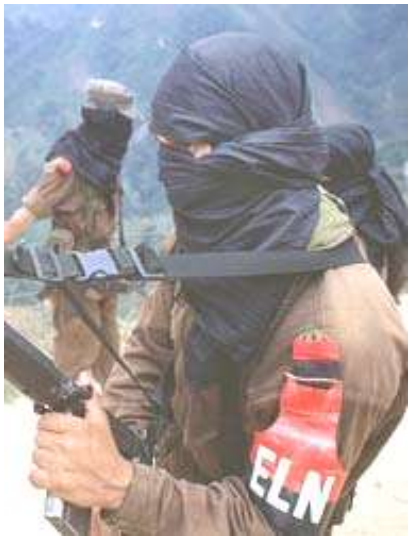

(Voces ELN, sf)

Como se puede percibir, en la imagen corporal actual (a la derecha), la pose del guerrillero transmite la figura del clásico guerrero, o sea, el ideal de un cuerpo joven, vigoroso, viril, en posición agresiva, con uniforme militar y empuñando su arma como demonstración de fuerza y poder. Entre los signos de exteriorización corporal (todas las fotos) hay un elemento clave: las armas, que son esenciales en la composición estética de estas imágenes, no como un objeto que se inscribe en el paisaje, sino como una prolongación del cuerpo del guerrero. Es parte de su identidad, que afirma su condición de agresividad. En efecto, las armas ocupan un lugar fundamental al interior de la organización que transciende la simple relación instrumental. Han sido objeto de una re-elaboración simbólica, revistiéndose de cierta sublimación por representar la posibilidad de materializar su proyecto de lucha: la toma del poder por vía bélica.

En síntesis, se podría afirmar que en la actualidad el tipo de corporalidad dominante en el ELN, es el de guerrero tradicional que exalta los valores de fuerza, agresividad y virilidad, inscrito en el molde del soldado moderno, con buena dotación y armamento, que transmite la imagen de ser militarmente competente para la guerra y que hace parte de una estrategia de confrontación. Asimismo, se pueden destacar entre los signos de identificación corporal, de un lado, las armas que poseen un alto valor pragmático y simbólico, y de otro, el uso de uniforme que mimetiza y homogeneiza a los militantes dentro de un formato corporal colectivo.

\section{Cuerpos para la guerra.}

Los cuerpos de los guerrilleros constituyen su primera y fundamental arma para la guerra. Por eso, es necesario acondicionarlos: entrenarlos, disciplinarlos, tecnificarlos. Son condiciones 
básicas para ser guerrillero, pues los ideales que orientan su lucha no son suficientes, necesitan que sus cuerpos sean resistentes, capaces de luchar y vencer. De ahí la importancia de aprender las técnicas corporales para la apropiación de este ethos.

El primer objetivo es obtener un buen estado físico, o sea: resistencia, potencia, fuerza, habilidad. Asunto que se torna complejo para los guerrilleros de origen urbano, cuyos cuerpos no están acondicionados a este tipo de exigencias físicas, razón por la cual muchas de sus narraciones enfatizan en las dificultades por las que pasan no sólo para adaptarse a esa vida, sino para ganar un lugar de respeto, pues ser guerrillero incluye y centraliza esta dimensión de la corporalidad.

El proceso de acondicionamiento corporal se lleva a cabo a través de dos planos de ejercitación física: en la vida cotidiana de la guerrilla y como rutina programada y dirigida. El buen estado físico se convierte en la base para el adiestramiento en las técnicas de lucha guerrillera, las cuales, en términos generales, se pueden sintetizar en tres aspectos: (a) desplazamiento y orientación en el territorio, (b) medidas básicas de observación, encubrimiento y guardia; (c) fundamentos de combate, ataque y retirada.

Con el aprendizaje de estas técnicas, los combatientes adquieren las destrezas necesarias para orientarse y caminar por el territorio de día y de noche, seguir los senderos y los atajos, vigilar y protegerse permanentemente $y$, sin duda, saber atacar y defenderse del enemigo. Esta es, de forma esquemática, la modalidad de "guerra de guerrillas" que los miembros de la organización deben aprender como parte de su nuevo modelo de corporalidad. Aunque reciban una instrucción básica cuando ingresan, es en la vida práctica cuando realmente incorporan este conjunto de técnicas.

Saber caminar es una de las cosas más difíciles para los citadinos: "en los momentos de cansancio aumenta el estrés, todos siguen caminando y tú te quedas atrás y tú no quieres que la tropa se atrase" (comunicación personal, 2008). Con el tiempo, los cuerpos se habitúan a esta rutina; el resto de las actividades relacionadas con el ejercicio de la guerra genera desafíos semejantes para todos los guerrilleros, pues en ellas ponen a prueba no sólo su competencia física, sino su nivel de compromiso y de firmeza, en la medida de que tales actividades contienen situaciones de riesgo en donde los sujetos se confrontan con el miedo. Dentro de estas actividades cabe destacar hacer guardia, definida por el grupo en los siguientes términos:

La Guardia es una medida defensiva del guerrillero para evitar ser sorprendido, poder detectar la presencia enemiga y reaccionar ante ello. Es una actividad de alerta y combate, que garantiza que una fuerza pueda desarrollar otras actividades como trabajo, sueño, descanso, producción, mientras se vela por su seguridad. El guardia son los ojos y oídos de los demás compañeros (Cartilla del combatiente eleno, itálica mía).

Es notorio el nivel de responsabilidad que adquiere el sujeto en posición de guardia. Cuida de la seguridad e integridad del grupo y, en este acto, textualmente, se transforma en el cuerpo colectivo - sus ojos y oídos. Es un momento de especial importancia en el que el sujeto interioriza este sentido de corporalidad centrado en lo colectivo. No se trata solamente de una cuestión física la capacidad de observación y reacción, sino en una actitud de firmeza para actuar frente a situaciones de riesgo: 
Esto es terrible, uno se enfrenta a todos los sustos, uno no sabe qué hacer; pero ya tener un arma y saber que responde por la vida de todos, uno todavía reza, oye todos los ruidos de la naturaleza y le parece que fueran pasos, resuellos, uno genera una tensión enorme, porque uno no domina el medio, uno no sabe qué va a pasar. Esa primera guardia es muy larga, es tensionante (comunicación personal, militante citadino, 2008).

Es una experiencia fuerte, al comienzo llega uno con ese temor de lo que pueda suceder, de cómo responder si hay una amenaza; y lo peor es cuando toca la guardia en la noche porque uno viene de esa cultura de creencias, que con el tiempo se va dando uno cuenta que las cosas no son así, que la religión se la ha infundido a uno en ese sentido. Entonces hay mucho temor, de los espíritus, el diablo, que los espantos (comunicación personal, militante rural, 2007).

A pesar de que varían el tipo de temores, en el caso del citadino por el desconocimiento de la naturaleza y en el caso del campesino por miedo a las apariciones sobrenaturales, en ambas situaciones prevalece la tensión frente al peligro y a la responsabilidad con el colectivo. En este tipo de desafíos, cuando los sujetos se enfrentan con sus propios miedos y limitaciones, es que se van transformando en militantes, asumiendo la dimensión ontológica de esta nueva identidad.

Sin embargo, la experiencia más intensa del aprendizaje de esta disciplina corporal se produce cuando participan en un combate. Allí se conjugan las diferentes técnicas corporales aprehendidas y se pone a prueba la preparación del sujeto a lo largo de su proceso de formación. Para comprender la magnitud de este evento en la vida de los guerrilleros, obsérvese las implicaciones de las reglas de oro que todos los combatientes deben obedecer: en primer lugar, estar a disposición permanente para el combate contra el enemigo, segundo, no abandonar la posición de combate sin que lo ordene el jefe superior y, tercero, la "prohibición de rendirse frente al enemigo", porque: "nuestro compromiso es LIBERTAD O MUERTE y con la misma convicción debemos enfrentar al enemigo, es necesario no claudicar ante la muerte" (Cartilla del combatiente eleno).

Bajo tales principios, se hace evidente el sentido de entrega total que los sujetos deben hacer a nombre de la organización, que lleva a estar dispuesto a sacrificar la propia vida. El cuerpo adquiere, así, la dimensión del sacrificio, como condición de ser y sentido de pertenencia al grupo.

Este es el significado que encierra el proceso de reconstrucción corporal centrado en el colectivo y en el ideal de la revolución. Aquí se pone a prueba todo el proceso preparatorio del individuo: su buen estado físico (fuerza, resistencia, agilidad), el adecuado adiestramiento en las técnicas y tácticas de combate, haber alcanzado "un alto grado de disciplina y moral para llegar hasta al máximo límite de resistencia" y contar con una "fortaleza personal para controlar el miedo y mantenerse en la acción" (Cartilla del combatiente eleno). Si el combatiente reúne estas condiciones, se puede afirmar que asimiló buena parte del aprendizaje que el proceso disciplinar militar de la organización dispone.

Pero, ¿cómo vivencia esta experiencia la persona? ¿Cómo consigue dominar el miedo? ¿Cómo enfrenta la muerte? Estas preguntas cobran relevancia en la medida de que la transformación del sujeto no sucede solamente en el plano de las destrezas físicas y técnicas, sino que también se expresa en la adopción de una nueva percepción sensorial, en una nueva forma de sentir y procesar sus emociones. En última instancia, de asimilar el miedo, de afrontarlo y superarlo. Véase el siguiente testimonio al respecto: 
Cuando dices que morirás y aceptas esto, tienes miedo, pero sientes que lo dominas, eso es un "estado alterado de consciencia". Yo lo averigüé después con la neurología, porque el cerebro segrega endorfina, adrenalina y todas esas cosas. Por ejemplo, cuando tú vas para una tarea y dejas cartas de despedida y se la entregas a tu compañero: esta es para mi madre, para mi hermana, para mi hijo, porque así lo hacen muchos, y sabes que puedes morir, pero vas feliz, y partes para la guerra, a la pelea o a la muerte. Eso es un estado alterado, pues si tú no tienes ese estado mental, no asumes ese papel. No es sólo un problema racional, se necesita sentir emoción, pues de lo contrario, no vas a la guerra, no lo soportarías. ¿Cómo soportas el sacrificio? ¿Cómo soportas la privación, el hambre? ¿Cómo continúas metido en medio de una pelea y no huyes, y aún dices: "o huimos o nos tiran muertos"? (Comunicación personal, exmilitante, intelectual, 2008).

La caracterización que esta militante hace de los "estados alterados de consciencia" denominación usada normalmente en Antropología para referirse al consumo de sustancias químicas que alteran el estado de la consciencia y que, en este caso, es provocado por la sobreexcitación del propio organismo - puede ser un interesante camino a explorar. De hecho, en el evento narrado, se observa una notable singularidad en la forma como se percibe y se asume el miedo ante la muerte. Va en contravía del instinto natural de supervivencia y de la propia formación sociocultural que enseña a protegerse y evitar, por encima de todo, la muerte.

Entonces, parece evidente que hay una "alteración" de ese tipo de consciencia o, mejor, de percepción de la misma. Esta "alteración" consiste básicamente en no huir de ese sentimiento como instintiva y culturalmente se haría, sino en confrontarlo hasta superar los umbrales que inmovilizan o hacen escapar. En este estado se vive la máxima exaltación, que orgánicamente se manifiesta a través del aumento de ciertas sustancias hormonales que mejoran la potencia y la resistencia corporal.

Por esta vía, me aproximé a la noción de flow que había abordado en una investigación sobre el tatuaje (Pérez, 2006), en cuyo contexto parecía adecuada para explicar la fuerte carga emotiva que las personas tienen (en casos de cobertura corporal avanzada) al momento de tatuarse y que les ayuda a superar y hasta disfrutar la sensación de dolor. Esta noción fue propuesta originalmente por Cskszentmihalyi y MacAloon como herramienta teórica para comprender las experiencias ocurridas en los juegos y deportes radicales, como también en las artes y en la religión, cuyo significado fue retomado por Turner (1982):

Flow denotes the holistic sensation present when we act with total involvement... a state which action follows action according to internal logic which seems to need no conscious on our part... we experience it as a unified flowing from one moment to the next, in which we feel in control of our actions, and in which there is little distinction between self and environment; between stimulus and response; or between past, present, and future (Turner, 1982, Pp. 55-56).

Aunque Turner (1982) hace algunas excepciones en cuanto al uso de este concepto, también destaca su valor explicativo en relación a las experiencias altamente emotivas vividas dentro de diversas situaciones y contextos, como el caso de las personas que siguen procesos de cobertura corporal (Pérez, 2006), pero también parecía apropiada para entender la experiencia vivida por los guerrilleros en momentos en que deben ir al combate o enfrentarse a situaciones de alto riesgo. 
¿Qué hace eficiente este concepto frente a tales contextos experienciales? Probablemente, su potencia explicativa radica en saber captar el carácter emocional de la experiencia: como sensación holística que envuelve completamente al sujeto y que genera un estado en el cual las acciones se realizan bajo una lógica interna distinta, donde más que la razón, se impone el flujo emotivo que embriaga al ser (Turner, 1982: 56). Este tipo de sensación es la que parece dominar en las experiencias descritas por los miembros del grupo en relación a los momentos en que enfrentan el miedo a la muerte: "Ese es un estado alterado, pues si tú no estás este estado mental, no asumes este papel. No es solamente un problema racional, es necesario estar emocionado, pues de lo contrario no vas a la guerra, no la soportarías" (Comunicación personal, 2008).

Otra característica importante y concomitante a esta experiencia, señalada por los autores que proponen este concepto, es la pérdida del ego, el self comienza a ser irrelevante en virtud a que el actor se encuentra totalmente inmerso en la experiencia flow y, por tanto, disminuye su interés por entender, definir o dirigir, actitud que, a su vez, propicia la fusión y el encuentro con el otro partícipe del acto (Turner, 1982: 57). Este análisis es oportuno para explicar, por el prisma de lo emocional, la forma como el combatiente se sale de los límites que protegen su self y se entrega a esta experiencia sin considerar los riesgos que ello atañe ni detenerse en la lógica social convencional; simplemente se deja llevar, entrando en comunión con el colectivo - parte del ideal de esta nueva subjetividad -, al punto de optar por el sacrificio, sentimiento bien sintetizado en esta frase dicha al calor del combate: "o salimos victoriosos o nos sacan muertos".

\section{Cuerpos para el sacrificio.}

Otro modelo de corporalidad presente en el grupo, que interacciona y refuerza el anteriormente visto del guerrero, es el que podría ser denominado como "monástico" para caracterizar el vínculo simbólico del ELN con la tradición cristiana y, especialmente, con algunos de los valores morales más preciados en dicho contexto organizativo como: la pureza, el ascetismo y el sacrificio. Este modelo fue alimentado y legitimado al interior del ELN por el sector cristiano y, principalmente, por la influencia ejercida por parte de los considerados "profetas" del grupo: los exsacerdotes Manuel Pérez y Camilo Torres (Pérez, 2008), quienes, además de constituir las mayores figuras icónicas de la organización, a través de ellos se sintetiza este modelo. Obsérvese la forma como reconstruyen sus imágenes corporales:

Figura n. 4 Sacerdote Camilo Torres.

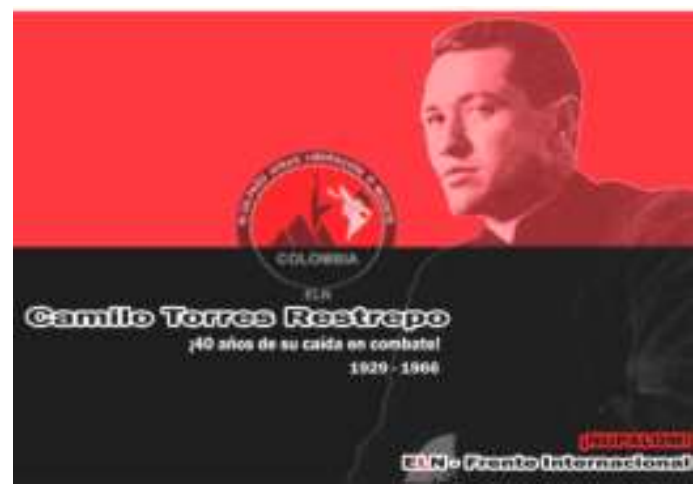

(Voces ELN, sf)
Figura n. 5. Sacerdote Manuel Pérez

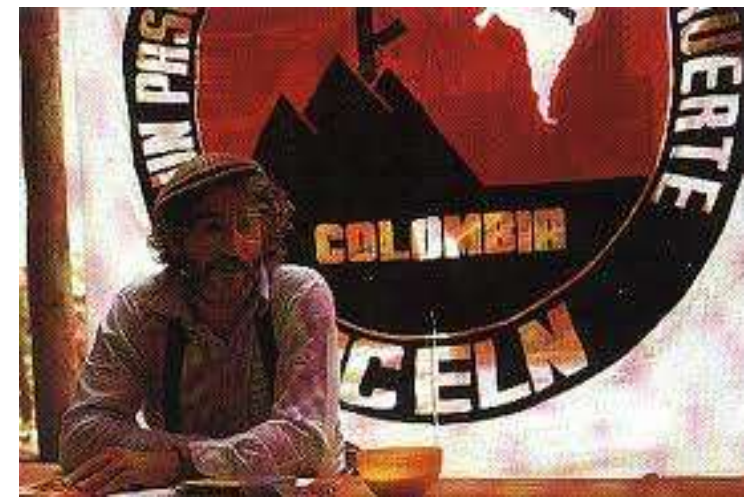

(Voces ELN, sf) 
Son evidentes las diferencias en relación a las imágenes recreadas de los guerreros, en este caso, los dos exsacerdotes aparecen sin los signos corporales de la guerra anteriormente vistos (armas y uniforme militar), destacándose otra perspectiva diferente: el lado carismático que los identifica y que se transmite a través de algunos detalles corporales como la profundidad de su miranda, la fuerza de su expresión, su actitud reposada, introspectiva, meditativa y algunas señales de su condición sacerdotal, como la sotana en el caso de Camilo.

Pero, el modelo corporal "monástico" no se identifica únicamente por los signos exteriores mencionados arriba, sino que incluye aspectos relevantes de la interacción personal como la postura, la performance comunicativa, el tono de la voz, la forma de dirigirse a los otros, características relacionadas con el esquema sacerdotal que se insertaron en el estilo de autoridad practicada al interior de la organización:

Claro, hay un lenguaje corporal, de la misa. Comienzan y hablan así: abren las manos, siempre demostrando paz y serenidad. Todo es pausado, sereno, persuasivo, casi sonoro. Esa era la forma como se comportaban los mandos: Manuel, Pacho, Antonio, Bautista, Pablo, Santiago, Milton, el Flaco [...] Ellos son así. El tono de voz es decisivo: sereno, pausado, para hablar claro, no muy fuerte, pero con autoridad, también el modo como te miran. Ellos nunca hablan con desatención, porque es necesario orientar, entonces es necesario convencerte [...] tiene un sentido de seducción, además de que hay una jerarquía, a ti te puede parecer la cosa más idiota pero después de que sea una orientación, se cumple y no mañana ni después, ahora (Comunicación personal, exmilitante, 2007).

Este modelo corporal tiene su máxima expresión en los llamados “profetas" (exsacerdotes fallecidos), se recrea en el sector de los mandos como forma de autoridad y se extiende para el conjunto de la organización como condición ejemplarizante. Esta corporalidad busca disciplinar las necesidades fisiológicas y encauzar la emotividad de la persona como estado sine qua non para alcanzar los objetivos revolucionarios. Es un valioso recurso simbólico para potencializar la resistencia del sujeto frente a situaciones difíciles, limítrofes.

Para alcanzar este ideal de dominio corporal, los militantes necesitan pasar por un proceso de adiestramiento que les permita incorporar las pautas de comportamiento de este nuevo estilo de vida. Es un proceso intenso, no sólo por la magnitud de lo que debe adquirir, sino por la confrontación que el sujeto debe hacer con los valores procedentes del modelo corporal interiorizado durante la socialización primaria. Ello implica hacer una ruptura radical con la forma anterior de percibir y vivenciar su corporalidad y, al mismo tiempo, reconstruir un nuevo sentido y una nueva praxis, cuyo proceso podría comprenderse bajo las siguientes dimensiones: el cuerpo puro, el cuerpo duro y el cuerpo del sacrificio.

\section{E1 cuerpo puro.}

Este cuerpo hace referencia a la valorización simbólica que subyace en el proceso de disciplinamiento de las necesidades corporales de orden fisiológico tales como el sueño, el cansancio, el hambre, la sexualidad, el frío, el calor. La forma de percepción de estas necesidades está asociada a la visión cristiana de entender al ser humano por el prisma de una dicotomía antagónica y asimétrica, esto es, de un lado, el cuerpo físico, relacionado con valores negativos tales como lo impuro, lo bajo, lo sucio y, de otro, el espíritu, relacionado con valores positivos como lo puro, lo noble, lo limpio. A través de esta dicotomía originaria, se establece una relación de poder del espíritu (lo puro) que debe controlar lo físico (lo impuro). Esta es la lógica simbólica 
transpuesta al contexto de esta organización, la cual, traducida a términos pragmáticos, significa el imperativo de controlar las necesidades físico-corporales como condición esencial de la lucha por sus ideales.

Para mantener un proyecto guerrillero, en la clandestinidad, en riesgo permanente y con innúmeras dificultades y limitaciones, es indispensable un reacondicionamiento corporal que asegure la supervivencia de sus miembros. Pero, la singularidad que aquí se quiere destacar es la manera como tales conductas corporales son vistas y asumidas: como virtudes depositarias de un alto valor revolucionario que demuestran la capacidad de entrega y de compromiso del militante. Por tanto, este no es un simple problema racional de supervivencia; tales actitudes están revestidas de una carga moral, deben ser expresiones de lo más noble y, en esa dirección, de lo más puro.

En contrapartida, alejarse de este modelo ideal implica caer en posiciones consideradas como degradantes y fuertemente condenadas por el grupo, que no solamente son castigadas, sino también juzgadas moralmente por el colectivo como una "falta de compromiso con la revolución" (comunicación personal, 2008). Se percibe, entonces, que se raciocina bajo la lógica de la dicotomía moralizante de lo indebido (impuro) y la protección sublimada del ideal revolucionario (puro). Así, tales valores, incrementados por la visión moral, actúan como potentes dispositivos simbólicos que refuerzan el proceso de aprendizaje de las actitudes y disposiciones corporales.

\section{El cuerpo duro.}

Otra dimensión que los militantes necesitan aprender a dominar es la emotividad. Es un nivel más complejo y exigente porque irrumpe en problemas culturales mucho más fuertes como el dolor, la pérdida, el sufrimiento, la muerte. Estos estados son condiciones permanentes, latentes, en el mundo de la guerra. Los militantes tienen que aprender a lidiar con estas cargas emocionales, aprender a soportar el dolor en todas sus expresiones - en lo físico, en las ausencias, en las pérdidas y, tal vez en lo más difícil, la muerte de sus compañeros y amigos. ¿Cómo consiguen llevar esas cargas tan pesadas? ¿Cómo se mantienen a pesar de esas penas tan duras? ¿Qué los alienta a seguir sin declinar, sin dejarse derrumbar? Véase la siguiente narración:

Así es con la revolución, es cuestión de enamorarnos de ese proyecto y de apostar la vida a él. Eso no quiere decir que no haya cosas muy duras. A mí me ha tocado duro, a mi papá lo desaparecieron. También me mataron a una hermana, la secuestraron, la degollaron y varios días después la encontramos toda descompuesta. Después me desplazaron la familia. Para ellos es muy duro que yo continúe aquí. Las presiones familiares son muy fuertes. También estuve en la cárcel por más de 5 año, y tuve poco apoyo de la organización, tal vez no por falta de voluntad sino por las condiciones, me trasladaron muy lejos, era una cárcel de alta seguridad, sufrí mucho; no hubo abogado de defensa, me tocó a mí, sin saber de eso. Pero, eso no lo puede desmotivar a uno. He puesto mi cuota, mi sacrificio, las cosas hay que hacerlas, conmigo o sin mí, yo aporto mi grano de arena. Uno dice: "si yo nací para algo, para hacer una obra, podría ser una casa y vivir en ella y tener 10 hijos". Pero, luego pienso que estamos haciendo una obra más colectiva, más grande: la revolución (comunicación personal, militante, 2007).

Esta historia es común en medio de la guerra, todos los militantes cargan a cuestas muchas historias tristes. No cabe duda de que sienten tristezas, el asunto radica en que aprenden a convivir con ellas, a pesar de ellas y por encima de ellas. El anterior testimonio permite entrever 
que, a pesar de los dolores y fracasos, eso "no los desmotiva” porque hay algo más fuerte, más poderoso que los mueve: la "revolución".

Pero, ¿qué es la revolución?, ¿qué dimensión adquiere en este contexto? Es la síntesis de su proyecto de vida y lucha, es la utopía, los ideales de libertad que los llevaron a empuñar las armas, y ellos, los protagonistas de ese gran ideal, se sienten llamados, responsables por esta causa. Aunque se pueda sustentar racionalmente los motivos del por qué y el para qué de la revolución, sus actitudes, testimonios y discursos permiten constatar algo más que potencializa esa fortaleza emocional y que, bajo este marco interpretativo, estaría estrechamente relacionado con el referente católico del cristo salvador, de asumirse y sentirse redentores del mundo, en una misión sin retorno, que parece estar marcada por el destino, en la que ellos son los elegidos para cumplir esa gran obra.

\section{El cuerpo sacrificial.}

En un mundo lleno de carencias materiales y de falta de comodidades, los militantes tienen que completar su aprendizaje con otro arte: la renuncia. Un arte que se inicia con el desprendimiento de las cosas materiales, los objetos, los utensilios, los accesorios. Las cosas pasan a ser vistas como simples "cosas", en su condición básica, elemental, en cuanto útiles para realizar determinadas actividades o suplir ciertas necesidades. Esto no significa que la renuncia lleve al vacío, a la ausencia o la pérdida. La renuncia es compensada, o mejor, cambiada por algo visto como superior: la superación de este sentimiento primario (y alienado para ellos) de tener por la incorporación, según su perspectiva, del sentimiento autentico de ser.

El ser significa ser más libres, poder llenar ese espacio de tener repleto de las cosas con otros valores como vivir intensamente el momento o estar en comunión con los otros (sentido básico para ellos), siempre en la perspectiva o en armonía con sus ideales máximos de lucha.

Estos ejercicios de desprendimiento de los objetos y del mundo material van preparando al sujeto frente a lo que será su renuncia mayor, la entrega de su máximo bien: su cuerpo, su vida. Esta será la verdadera prueba de su capacidad de renuncia, su propio sacrificio como una ofrenda suprema a ese ideal: el pueblo y la revolución. Sin dolor, sin pena, conforme lo expresa claramente una militante: "Tengo consciencia de que yo también quedaré aquí, porque mi amor es entregar mi vida por esto", porque, como dicho encima, cambian ese valor del tener por el de ser y, en este caso, el de ser para el más allá, el de consagrarse como mártires y ejemplos de la revolución.

\section{Subjetividad y corporalidad.}

Entendiendo por subjetividad la formación de conciencias complejas de pensamiento, sentimiento y reflexión, bajo determinados contextos y prácticas culturales (Ortner, 2006), cabe preguntarse por el tipo de conciencia que se construye en esta organización político-militar. Conforme los datos recogidos, podría conjeturarse que la subjetividad del grupo tiene cercanía con el modelo de clasificación social propuesto por Dumont (1970) para el caso de la India: el bolismo social, que consiste en una ideología cuyo orden normativo "le asigna el valor supremo a la totalidad social por encima del individuo a quien ignora" (Stolcke, 2001, p. 18). 
Pero, a diferencia de la sociedad de castas de la India, fundamentada en la lógica jerárquica: "la casta es el vínculo social determinante que se encuentra en la base de las relaciones sociales [...] el principio de jerarquía es omnipresente en el sistema de castas" (Stolcke, 2001: 18), en el caso del ELN, el orden social se rige por valores primos como la justicia social y la construcción de una sociedad socialista igualitaria, donde cobra una marcada centralidad lo colectivo. Se estaría hablando, entonces, de una subjetividad condicionada por la noción de bolismo social igualitario.

Si se asume este presupuesto, se estaría planteando que el pensamiento y la lógica de actual de este grupo se moldea por ese pilar ideológico que transversaliza y dota de significado su mundo. Los puntos de inflexión que articulan este sistema de pensamiento reposan en cuatro referentes principales, a saber: la revolución, el pueblo, la organización y el colectivo.

La revolución es una categoría social fuertemente semantizada y situada en el tope de sus valores. Se le transfiere un sentido supremo, transcendente, sublime que sintetiza y representa su máximo ideal: la construcción de una sociedad socialista igualitaria. Por su parte, el pueblo es considerado el sujeto histórico de la revolución, en quien se concentra y se proyecta el ideario de lucha. La organización, forma genérica como ellos se conciben y nombran, constituye la mediación de este ideal de lucha y la acción, en cuanto ellos se consideran los elegidos, los salvadores, que hacen posible la construcción social de ese ideal.

Finalmente, el colectivo, comprendido como los sujetos de la acción de este modelo, puede ser visto a través de dos niveles de interpretación: como valor central de su pensamiento y como existencia concreta de su campo de interacción, cuya unidad más significativa son los llamados "colectivos político-militares". Estos colectivos constituyen, conforme su reglamento interno, la forma como se concibe el ser y el estar dentro de la organización: "Los miembros del ELN están organizados en colectivos político-militares y sujetos al plan de trabajo" (Artículo 3, Estatutos, 2006).

Cabe resaltar, asimismo, que esta visión del mundo no se formula desde sí y para sí, sino que siempre está en contraposición con el modelo individualista dominante en la sociedad Occidental.

En este modelo social se maximiza el valor del individuo: "El individualismo es una forma particular de producción cultural que consiste en practicar la regla inversa del holismo: no es la relación lo que prima, como objeto de interés, sino el individuo sustancializado como entidad autónoma" (Díaz, 2003, p. 248).

El ELN se piensa y se edifica sobre este sentido de oposición y confrontación, viéndose a sí mismo como la vanguardia que junto al pueblo (sujeto histórico), luchan por la transformación de ese modelo individualista considerado como capitalista, alienante, consumista, desigual, injusto.

En este proceso de confrontación, visto como un camino de liberación, ellos se asumen y se construyen como los sujetos ideales, o mejor, como el sujeto colectivo por excelencia. Por eso, todo su esquema de interacción y de construcción simbólica reposa sobre tales principiosvalores. Así, se modela la nueva subjetividad aquí descrita. 
Este aspecto ayuda a visibilizar el hecho de que el modelo validado por el grupo -el igualitarismo social, también está refrendado sobre valores que se vuelven dominantes en este contexto social al punto de naturalizarse $\mathrm{y} / \mathrm{o}$ esencializarse, lo cual no se corresponde completamente con su modus vivendi. De modo que, a pesar de que los miembros del grupo actúen en la práctica bajo diferentes formas de clasificación jerárquica, ellos se piensan y se definen con base en el valor del social-igualitarismo.

Pero, ¿cómo es la forma en que los miembros del grupo conciben e internalizan dicha lógica y ética social? En realidad, este fue un aspecto bastante complejo de abordar en la investigación, pues, los miembros del grupo no se asumen como sujetos bajo la dimensión individualista que estamos acostumbrados a pensarnos. Por eso, durante reiteradas ocasiones surgía el interrogante sobre el espacio "personal" de los militantes, ya que, como ellos lo relataban, parecía una renuncia al yo. Asunto que se hacía aún más paradójico por el hecho de que este aspecto no parecía ser problemático para ellos, así como se puede observar en el siguiente diálogo:

\section{-Sobre la "renuncia" ¿qué piensas?, ¿cómo fue la tuya al ingresar a la organización?}

La verdad, son renuncias que a la vez no son renuncias, son ganancias y los demás lo ven como renuncias, pero para uno es lo que le está permitiendo vivir y crecer. Yo peleo con muchos líderes sociales o las esposas de algunos dirigentes que les ha tocado esconderse durante muchos años y ellas se quejan de que ellos le han dejado todo a la gente, que se han sacrificado por la gente para que la gente no le pague bien. Yo les digo: "no se han sacrificado por la gente, él lo ha hecho por él". Porque esto a mí me llena, porque si no estuviera haciendo esto yo no me sentiría completa ni útil como persona.

-Pero, ¿qué queda de ese sujeto individual?

Le voy a decir lo que decía un campesino: "yo antes solamente me preocupaba de mi parcela, hoy me estoy preocupando de la comunidad, ahora estoy entendiendo que hay una construcción social", porque en la medida de que va entendiendo, más se da cuenta que tiene que buscar a otros para impregnarlos de eso y que entre todos vamos construyendo. Que soy líder, pero es un líder con los otros, y que si soy autónomo es una autonomía, pero vivida con los demás, sin perder mi individualidad, pero mi individualidad también siempre está referida al otro (Diario personal, 2008).

De esta manera, fue quedando cada vez más evidente que en esta opción de vida no parecía haber traumatismos ni un sentido de renuncia, tal como se podría pensar desde la lógica individualista, como tampoco de la nostalgia por lo que podría haber sido o hecho, en la medida de que ese espacio no está vacío; está ocupado por la otredad. Luego, su sentido de vida se construye en relación a los otros y con referencia al colectivo. Un sentido que no aparece espontáneamente, como un voto de pertenencia o una insignia de adhesión al grupo, sino que se edifica a través del proceso vivencial, de la convivencia, de la inmersión en ese mundo. Esta es una importante dimensión que permite hablar de la existencia de una forma distinta, no individualista, de percibir las cosas. En el acto de "estar juntos" todo el tiempo, de convivir permanentemente como colectivo, se producen las condiciones que crean y solidifican esta nueva subjetividad.

El sentido de lo colectivo adquirido en la convivencia y en la consolidación de lazos de afectividad, también se procesa y se refuerza en el ejercicio político de la militancia, entendida como la asunción de responsabilidades, las cuales se sustentan en el principio de saber pensar y actuar en función del grupo. Pues, todas las acciones que se realizan dentro de este contexto social involucra a los otros, sea en cosas aparentemente simples como cocinar hasta hacer la guardia, se está poniendo en juego la seguridad y preservación del grupo. Así, en el acto de asumir 
responsabilidades en, de y para el colectivo, el sujeto construye su compromiso con la organización y, por este camino, avanza en el proceso de volverse militante, o sea, eleno, tal como ellos lo entienden. Es decir, de solidificar ese sentimiento de "ser parte de" que está estrechamente vinculado con la búsqueda de colectivizarse como pensamiento y como acción.

No podía faltar la reflexión sobre la palabra: el poder creador de nombrar y recrear el mundo a partir del principio fundador de lo colectivo. Sus discursos argumentativos están construidos sobre un sistema de categorías y nociones referidas al todo social, que tejen y traducen su pensamiento. Pero, probablemente, lo que puede representar mejor la apropiación de esta perspectiva en el lenguaje es el tipo de uso y revalorización que hacen del pronombre personal Nosotros. Se piensan y hablan bajo esta categoría, al punto de que se puede afirmar que el yo pierde sentido, aparece débil; es prácticamente inexistente en su vocabulario. Aspecto que se puede verificar en sus discursos orales o escritos, en los cuales el yo desaparece casi completamente, pues siempre se refieren a sí mismos como nosotros - implicando con ello a la organización, a los militantes, a los revolucionarios, al pueblo etc. Igualmente, sucede cuando se dialoga con ellos, sus narrativas tienden a evocar la noción de proceso, la acción colectiva, el proyecto político o las anécdotas grupales.

Cuando se hacía preguntas más directas a los militantes que implicaban tomar posición, respondían a través de la voz de la organización, sea bajo la forma del nosotros como colectivo concreto o como a organización en su sentido general. No era fácil que se autocentraran; les costaba hablar de ellos mismos, por eso, se hacía necesario ir y regresar en la argumentación para intentar retener algunas referencias personales. Se constató, así, la dificultad de indagar en este contexto social desde el modelo individualista, porque allí el sujeto privilegiado de la acción es el colectivo. En resumen, no se trata de que el yo se encuentre alienado bajo el manto de lo social, sino que este valor se había transformado en el Nosotros, como noción central constructora de esos sujetos y como expresión de su subjetividad.

Finalmente, una dimensión fundamental en la que el sentido de lo colectivo gana vida y se transforma en una conducta internalizada por los miembros del grupo, es la corporalidad. Los cuerpos son reconstruidos y resignificados a partir de la noción de lo social como valor determinante. Por ello, conforme visto, sus signos corporales más visibles son los grupales: el uso del uniforme y de las insignias características del ELN, en virtud de que no buscan resaltar al individuo sino al sujeto colectivo; es este quien cobra presencia y ocupa un lugar diferenciado en el mundo. Asimismo, todas sus técnicas y disciplinas corporales se dirigen hacia la "incorporación" de lo social, hasta alcanzar su máxima potencialización con el propio sacrificio, a través del cual los cuerpos se convierten en la ofrenda mayor, superior, de entrega total al ideal revolucionario como forma de transcendencia del colectivo.

\section{Bibliografía.}

Aguilera, M. (2003). La memoria y los héroes guerrilleros. Análisis Político(49), 3-27.

Aguilera, M. (2007). ELN: entre las armas y la política. En F. Gutiérrez, Nuestra guerra sin nombre. Transformaciones del conflicto en Colombia. Bogotá: Editorial Norma.

Aranguren, J. P. (2006). Las inscripciones de la guerra en el cuerpo: evidencias de un sujeto implicado . Revista Colombiana de Psicología(15), 103-112. 
Bejarano, E. (2005). Camilo Torres Restrepo hoy en día, una visión del Ejército de Liberación Nacional ELN. Monografía de pregrado en Antropología. Bogotá: Universidad Nacional de Colombia.

Berger, P., \& Luckmann, T. (1976). A construção social da realidade. Tratado de sociologia do conhecimento. Petrópolis: Vozes.

Broderick, W. (1977). Camilo Torres: el cura guerrillero. Bogotá: Círculo de Lectores.

Broderick, W. (2000). El guerrillero invisible. Bogotá: Intermedio.

Castro, M. C. (2002). Investiduras, destrozos y cicatrices o del cuerpo en la guerra. Desde el Jardín de Freud, 38-45.

DaMatta, R. (1983). Carnavais, Malandros e Heróis. Para uma sociologia do dilema brasileiro. Rio de Janeiro: Zahar editores.

DaMatta, R., Seeger, A., \& Viveiros de Castro, E. (1979). A construção da Pessoa nas sociedades indígenas brasileiras. Boletim do Museu Nacional(32), 2-19.

Díaz, A. (2003). Las formas del holismo. La construcción teórica de la totalidad en etnografía. Revista de Dialectología y Tradiciones Populares, 58(1), 237-262.

Díaz, C. L. (2003). Destrucción del cuerpo: de la fantasía al acto. Desde El Jardín de Freud(2), 2037.

Foucault, M. (1987). Vigiar e punir. Petrópolis: Vozes.

Harnecker, M. (1988). Unidad que multiplica: entrevista a dirigentes máximos de la Unión Camilista Ejército de Liberación Nacional. Quito: Quimera Ediciones.

Le Breton, D. (1995). Antropología del cuerpo y modernidad. Buenos Aires: Nueva Visión.

Londoño, L. M. (2005). La corporalidad de las guerreras: una mirada sobre las mujeres combatientes desde el cuerpo y el lenguaje. Revista De Estudios Sociales(21), 67-74.

López, M. (1989). Camilo camina en Colombia. Colombia: Ediciones Rústicas.

Maluf, S. (2002). Corpo e Corporalidade nas culturas contemporâneas: abordagens antropológicas. Esboços (UFC) (9), 87-101.

Mauss, M. (1991). Sociología y Antropología. Madrid: Tecnos.

Medina, C. (1996). ELN: Una historia contada a dos voces. Bogotá: Rodríguez Quito Editores.

Medina, C. (2001). Elementos para una historia de las ideas políticas del ELN. Bogotá: Rodriguez quito editores. 
Ortner, S. (2006). Anthropology and Social Theory. Culture, power, and the acting subject. London: Duke University Press.

Pérez, A. L. (2006). A identidade à flor de pele: Etnografia da prática da tatuagem na contemporaneidade. Revista MANA, 12(1), 179-206.

Pérez, A. L. (2008). O sentido de ser guerrilheiro: Uma análise antropológica do Exército de Libertação Nacional da Colômbia. Florianópolis: Universidad Federal de Santa Catarina.

Stolcke, V. (2001). Gloria o maldición del individualism moderno según Louis Dumont. Revista de Antropologia, 44(2), 8-37.

Turner, V. (1982). Liminal to liminoid. in Play, Flow, and Ritual: An Essay in Comparative Symbology . En From Ritual to Theatre: The Human Seriousness of Play. New York: PAJ.

Uribe, M. T. (2001). Las guerras por la nación en Colombia durante el siglo XIX. Revista de Estudios Políticos(18), 9-27.

Vargas, A. (1992). Colonización y conflicto armado. Magdalena Medio Santandereano. Bogotá: Cinep.

Vargas, A. (1998). Una mirada analítica sobre el ELN. Controversia(173), 100-120. 